\title{
Electrochemical performance of supercapacitor with glass wool separator under $\mathrm{TEABF}_{4}$ electrolyte
}

\author{
Mohd Ferdaus Mohammad Yaacob ${ }^{1}$, Zulkarnain Ahmad Noorden², \\ Muhammad Nizam Abdul Razak ${ }^{3}$, Zuraimy Adzis ${ }^{4}$, Jasrul Jamani Jamian ${ }^{5}$ \\ ${ }^{1,5}$ School of Electrical Engineering, Faculty of Engineering, Universiti Teknologi Malaysia, Malaysia \\ ${ }^{2,3,4}$ Institute of High Voltage \& High Current, Universiti Teknologi Malaysia, Malaysia
}

\section{Article Info}

Article history:

Received Dec 27, 2019

Revised Feb 7, 2020

Accepted Apr 29, 2020

\section{Keywords:}

Electrical double layercapacitor specific capacitance Glass wool separator Organic electrolyte

\begin{abstract}
The paper presents the electrochemical performance of supercapacitor with glass wool separator under organic electrolyte of tetraethylammonium tetrafluoroborate $\left(\mathrm{TEABF}_{4}\right)$. The performance was evaluated using symmetrical two-electrode system and compared to an identical supercapacitor with commercially available cellulose paper separator under 1 $\mathrm{M} \mathrm{TEABF}_{4}$. The application of glass wool separator reduces the bulk resistance of supercapacitor by $19.6 \%$, promotes more efficient ions transfer across active surface of electrode and significantly improves specific capacitance by $19.1 \%$ compared to cellulose paper. The application of higher concentration $\mathrm{TEABF}_{4}(1.5 \mathrm{M})$ even improves the overall performance of glass wool-based supercapacitor by $32.2 \%$ reduction of bulk resistance and $61.9 \%$ increment in specific capacitance compared to $1 \mathrm{M} \mathrm{TEABF}_{4}$. In addition, the energy and power densities are significantly improved by $64 \%$ and $165 \%$, respectively for the one with $1.5 \mathrm{M} \mathrm{TEABF}_{4}$. In general, the low-cost material glass wool material has great potential to replace commercially available cellulose paper as separator in developing much better supercapacitor.
\end{abstract}

This is an open access article under the CC BY-SA license.

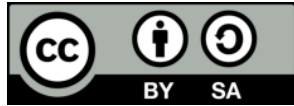

\section{Corresponding Author:}

Zulkarnain Ahmad Noorden, Institute of High Voltage \& High Current,

School of Electrical Engineering,

Universiti Teknologi Malaysia,

UTM Skudai 81310, Johor, Malaysia.

Email: zulkarnain-an@utm.my

\section{INTRODUCTION}

Separator in a supercapacitor serves as an inactive critical component and plays important role in determining the supercapacitor's electrochemical performance. Apart from preventing short circuit between positive and negative electrodes, separator facilitates the path for ions migration and retains the electrolyte permanently for ionic conductivity between the electrodes [1-4]. There are several critical requirements for the separator such as; (1) having a strong electrical insulation with minimal resistance for ion transfer within electrolyte; (2) high chemical and electrochemical stabilities; and (3) good mechanical strength for device durability [1]. Commonly, separator such as cellulose paper is known to operate well in organic electrolyte however its ageing process eventually would accelerate when sufficient amount of water is present in the electrolyte [5]. In addition, cellulose paper is not able to withstand high concentration aqueous electrolyte in supercapacitor application [6]. The utilization of high concentration electrolyte is the future attempt for researcher to improve energy and power density of supercapacitor as well proven by previous researchers [7-10]. 
The low cost material, glass wool has been introduced by Z. A. Noorden et al. as potential separator for supercapacitor application [11]. Unlike cellulose paper, glass wool is made from recycle glass and possesses good mechanical strength and besides being corrosive resistant, glass wool has more effective conductivity for ions electrolyte compared to cellulose paper, which is a favorable characteristic for separator [6]. Nevertheless, to the best of our knowledge, there are no report on the electrochemical performance of supercapacitor with glass wool separator under organic electrolyte. Herein, we report the systematic evaluation of electrochemical performance of supercapacitors with glass wool separator under 2 different concentrations of organic electrolyte of $1 \mathrm{M}$ and $1.5 \mathrm{M}$ tetraethylammonium tetrafluoroborate $\left(\mathrm{TEABF}_{4}\right)$. For comparison, the electrochemical performance of supercapacitor with cellulose paper separator were also performed under $1 \mathrm{M} \mathrm{TEABF} 4$. The performance of supercapacitor (i.e. specific capacitance, internal resistance, power and energy densities) is assessed by means of cyclic voltammetry (CV), galvanostatic charge-discharge (GCD) and cyclic charge-discharge (CCD) tests, and electrochemical impedance spectroscopy (EIS).

\section{EXPERIMENTAL WORKS}

Referring to Figure 1, a symmetrical EDLC was constructed in a custom-made two-electrode coin-type test cell. A corrosive-resistant glass wool (CNBM International Corporation, China) was used as the separator, inserted between two activated carbon sheets (Nippon Valqua industries Ltd., Japan) as active electrodes. The activated carbon sheets used in this study has a Brunauer-Emmett-Teller specific surface area (BET SSA) of $1141.5 \mathrm{~m}^{2} / \mathrm{g}$ and exhibit type IV isotherms (mesoporous) according to the International Union of Pure and Applied Chemistry (IUPAC) classification, as shown in Figure 2.

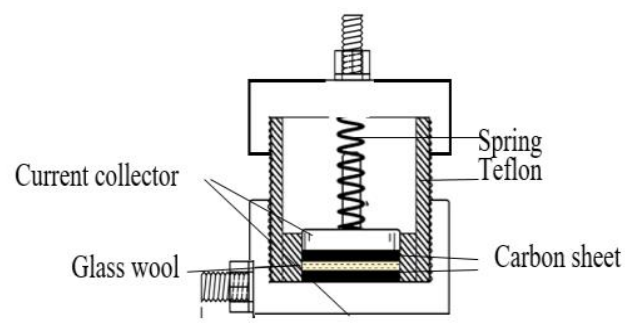

Figure 1. Schematic diagram of the test cell construction

Prior to the construction, cellulose paper and glass wool were cut in a circular shape and separately moistened with $\mathrm{TEABF}_{4}$ electrolytes according to the molarity. TEABF 4 was synthesised in our lab by mixing with acetonitrile as solvent to make different molarity solutions.

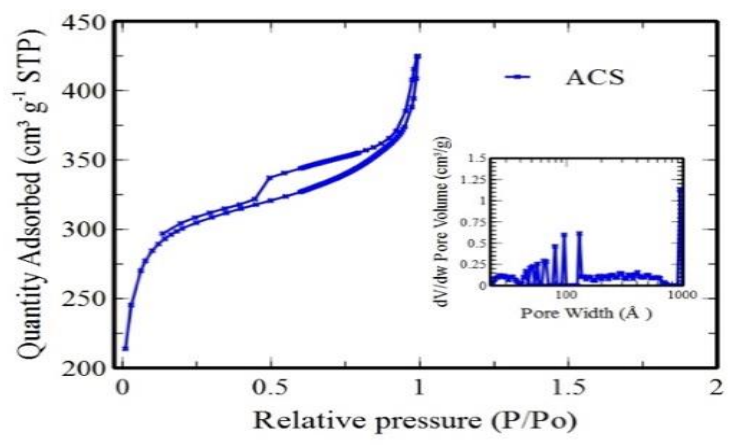

Figure 2. $\mathrm{N}_{2}$ adsorption/desorption isotherms and pore size distribution of the activated carbon sheets (see inset)

The constructed glass wool-based EDLCs were characterized through CV, GCD, EIS and cyclic charge-discharge tests using an electrochemical measuring system, Gamry Interface 1000 potentiostat (Gamry Instrument, USA). All measurements were carried out at room temperature condition between $25^{\circ} \mathrm{C}$ and $28^{\circ} \mathrm{C}$. The $\mathrm{CV}$ test was performed at 3 different scan rates of 1,2 , and $5 \mathrm{mV} / \mathrm{s}$ within a potential range between 0 and $2.7 \mathrm{~V}$. The GCD test was performed at $2 \mathrm{~mA}, 5 \mathrm{~mA}$, and $10 \mathrm{~mA}$ constant current supplied

Electrochemical performance of supercapacitor with glass wool... (Mohd Ferdaus Mohammad Yaacob) 
within a potential window of 0 to $2.7 \mathrm{~V}$. The EIS test was carried out to further investigate the performance of glass wool-based supercapacitors in different $\mathrm{AC}$ frequency region ranging from $1 \mathrm{mHz}$ to $100 \mathrm{KHz}$ at a DC bias of zero volts. A typical Nyquist curve consists of three regions: (1) a high frequency region with a semi-circle curve which is influenced by the resistive and capacitive component; (2) a medium frequency region that is indicated by a $45^{\circ}$ slope, which describes the charge accumulation process into the porous surface of the activated carbon electrodes; and (3) a low frequency region that is indicated by a nearly vertical line, which describes the capacitive response of the supercapacitor. The diameter of the semi-circle represents the internal series resistance, $R_{e s r}$ [12-18]. Power density, $P_{d}(\mathrm{~W} / \mathrm{kg})$, and energy density, $E_{d}$ $\left(\mathrm{Wh} / \mathrm{kg}\right.$,) were estimated based on the potential window, $V(\mathrm{~V})$, the total mass of carbon electrodes, $m_{t}(\mathrm{~g})$, the average values of the absolute capacitance, $C(\mathrm{~F})$, and internal resistance, $R_{e s r}(\Omega)$, obtained from the $\mathrm{CV}$, GCD, CCD, and EIS measurements [11].

\section{RESULTS AND DISCUSSION}

Figure 3(a), (b) and (c) shows the CV curves for constructed supercapacitors with glass wool and cellulose separator at different voltage scan rates of $1,2,5 \mathrm{mV} / \mathrm{s}$. Overall, all constructed supercapacitor shows symmetrical quasi rectangular CV curves with no redox peak indicating typical electric double layer behaviour. Supercapacitor with cellulose paper separator containing $1 \mathrm{M} \mathrm{TEABF}_{4}$ electrolyte is observed to exhibit high resistive character towards increasing the scan rates from $1 \mathrm{mV} / \mathrm{s}$ to $5 \mathrm{mV} / \mathrm{s}$ as we can see the shape of the CV curves distorted with increasing voltage scan rates compared to glass wool-based supercapacitor. Table 1 tabulates the approximate specific capacitance computed from the CV curves [6] and the dependency of these capacitance values on the applied scan rates is shown in Figure 3(d). It can be observed that the static specific capacitance for $1 \mathrm{M} \mathrm{TEABF}_{4}$ with glass wool separator is $83.6 \mathrm{~F} / \mathrm{g}, 12 \%$ higher than cellulose paper $74.6 \mathrm{~F} / \mathrm{g}$ at $1 \mathrm{mV} / \mathrm{s}$. This indicate application of glass wool separator in organic electrolyte facilitate good ion propagation and improves the capacitive characteristic of supercapacitor. Concurrently, the supercapacitor with glass wool separator under $1.5 \mathrm{M} \mathrm{TEABF}_{4}$ exhibit $85.5 \mathrm{~F} / \mathrm{g}$ which is $15 \%$ improvement of specific capacitance at the same $1 \mathrm{mV} / \mathrm{s}$ scan rate. The typical trend of electrochemical capacitor observed when increasing the scan rate, the value of static capacitance of each supercapacitor were degraded due to lack of time for ions to diffuse into the inner surface of electrode [19-22].

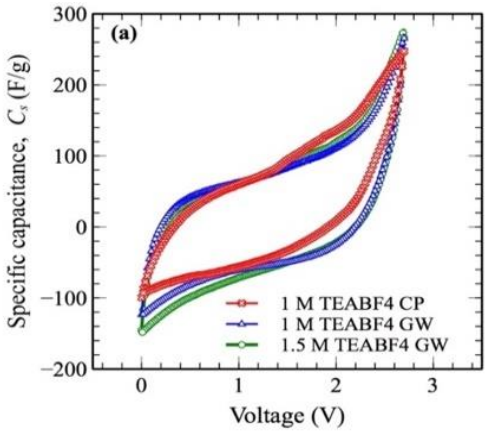

(a)

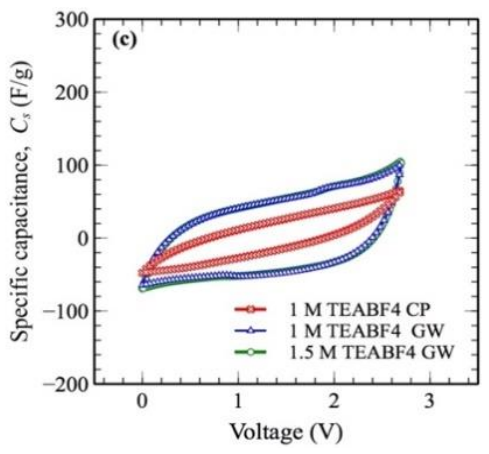

(c)

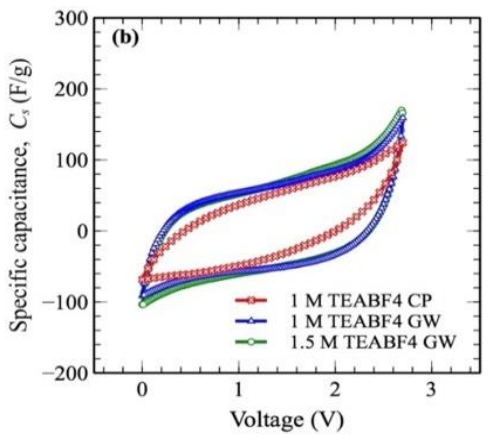

(b)

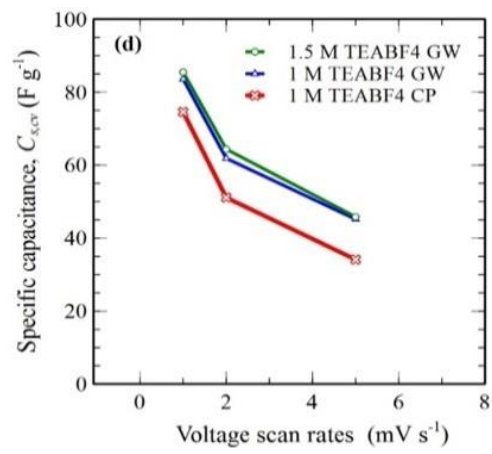

(d)

Figure 3. CV curves for a voltage scan rates of (a) $1 \mathrm{mV} / \mathrm{s}$, (b) $2 \mathrm{mV} / \mathrm{s}$, (c) $5 \mathrm{mV} / \mathrm{s}$, (d) Static specific capacitance versus scan rates 
The charging and discharging curves of supercapacitor at different current supply are shown in Figure 4(a), (b) and (c). The nearly-triangle shape of voltage responses justifies the good double layer capacitance characteristic observed in CV curves. The charge-discharge curves show that the glass wool separator required more time to charge and discharge compared to cellulose separator indicates good capacitive properties. As tabulated in Table 1 and shown in Figure 4(d), the highest capacitance value was obtained at $2 \mathrm{~mA}$ in $1.5 \mathrm{M} \mathrm{TEABF}_{4}$ electrolyte, $53.1 \mathrm{~F} / \mathrm{g}$ followed by cellulose and glass wool based super capacitor in $1 \mathrm{M} \mathrm{TEABF}_{4}$ which are $36.8 \mathrm{~F} / \mathrm{g}$ and $32.8 \mathrm{~F} / \mathrm{g}$, respectively. As reported by Tsay et al. the high number of ions available has made the transportation of ions within the electrode layers easier, leading to an effective accumulation of ions and electrons and hence increase the capacitance [23]. However, as observed in Figure 4(d) the specific capacitance for cellulose based supercapacitor is drastically decreased as the current supply increased as compared to glass wool-based supercapacitor at the same electrolyte concentration. The study suggests that the porosity available in the glass wool material and ability to retain electrolyte improves the ion transportation during charge discharges hence improving capacitance properties even at high current.

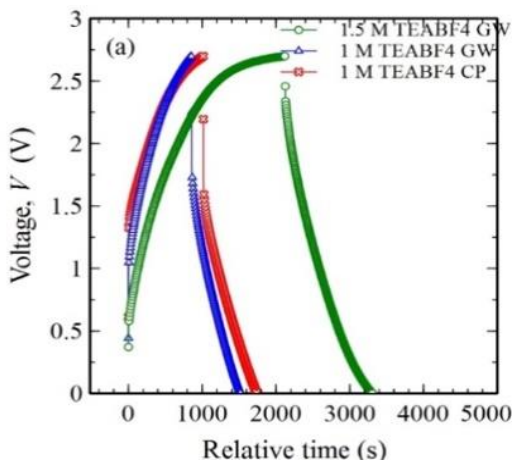

(a)

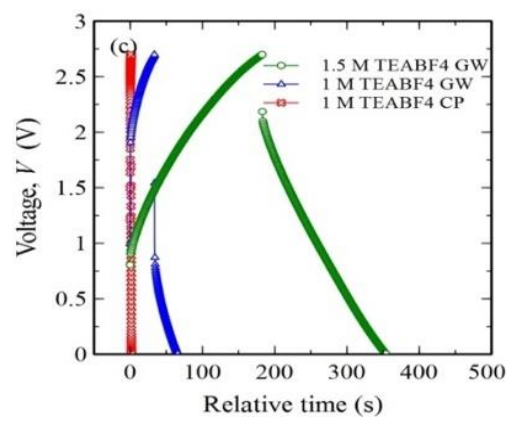

(c)

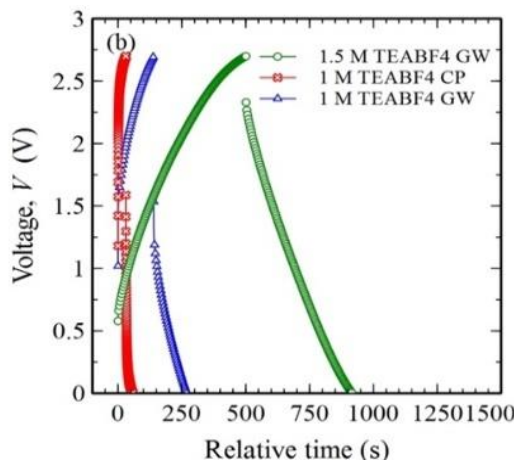

(b)

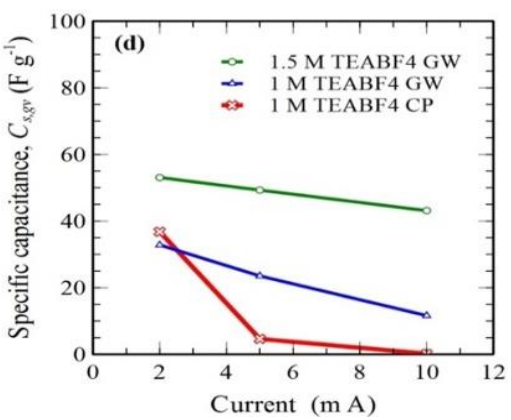

(d)

Figure 4. Galvanostatic charge-discharge curves for a supply current of (a) $2 \mathrm{~mA}$, (b) $5 \mathrm{~mA}$,

(c) $10 \mathrm{~mA}$ and (d) Static specific capacitance at different supply current

Figure 5(a) shows the Nyquist plot of the measured AC impedance for supercapacitors with glass wool and cellulose paper separator respectively. A depressed semicircle was observed in high frequency region, which represent a combination of resistive and capacitive component. As shown in Table 1, compared to cellulose based supercapacitor, the charge transfer resistance or equivalent series resistance, $R_{e s r}$ for glass wool-based supercapacitor was estimated around $104 \Omega$ which is $19.5 \%$ smaller than cellulose based supercapacitor, $129.2 \Omega$ under $1 \mathrm{M} \mathrm{TEABF}_{4}$. The finding suggests that high porosity of glass wool material and ability to retain electrolyte improves the ion mobility, thus improving charge transfer resistance. Meanwhile, supercapacitor with $1.5 \mathrm{M} \mathrm{TEABF}_{4}$, the $R_{e s r}$ is even better at $70.5 \Omega$ with $32.2 \%$ reduction. The variation of specific capacitance against frequency can be observed in Figure $5(\mathrm{~b})$. The specific capacitances were estimated at very low frequency, which is nearly to its DC properties. The result reveals supercapacitor with glass wool exhibits $19.1 \%$ improvement at $33.1 \mathrm{~F} / \mathrm{g}$ compared to supercapacitor with cellulose paper, $27.8 \mathrm{~F} / \mathrm{g}$ under $1 \mathrm{M} \mathrm{TEABF}_{4}$. The superior specific capacitance $(40.0 \mathrm{~F} / \mathrm{g})$ of supercapacitor with $1.5 \mathrm{M}$

Electrochemical performance of supercapacitor with glass wool... (Mohd Ferdaus Mohammad Yaacob) 
$\mathrm{TEABF}_{4}$ is in good agreement to that of from CV and GCD tests with $22 \%$ improvement as compared to other supercapacitors.

Figure 5(d) show the bode plot of the contructed supercapacitors, indicating the response time above $45^{\circ}$ phase at the $\mathrm{AC}$ frequency of $1 \mathrm{mHz}$. The curves reveal that glass wool-based supercapacitor with $1.5 \mathrm{M}$ $\mathrm{TEABF}_{4}$ gives the faster response time followed by glass wool-based supercapacitor under $1 \mathrm{M} \mathrm{TEABF}_{4}$. The glass wool-based supercapacitor under $1.5 \mathrm{M} \mathrm{TEABF}_{4}$ is observed to be close to $70^{\circ}$ at low frequency which indicate nearly pure capacitive behavior of supercapacitor which is ideal at $90^{\circ}$. The frequency at the maximum peaks of imaginary part of the complex capacitance $C^{\prime \prime}(\mathrm{F})$ shown in Figure 5(c) can be used to estimate the time constant of supercapacitor. The frequency at the maximum peak were measured at 1.3, 1.6, $2.5 \mathrm{mHz}$ for $1 \mathrm{M} \mathrm{TEABF} 4$ cellulose-, $1 \mathrm{M} \mathrm{TEABF}_{4}$ glass wool-, and $1.5 \mathrm{M} \mathrm{TEABF}_{4}$ glass wool-based supercapacitors, respectively. The corresponding relaxation time [11, 17] reveals that glass wool-based supercapacitor has faster relaxation time $(99.5 \mathrm{~s})$ compared to cellulose based supercapacitor (126.3 $\mathrm{s})$ under $1 \mathrm{M} \mathrm{TEABF}_{4}$. The relaxation time is even faster under $1.5 \mathrm{M} \mathrm{TEABF} 4(63.7 \mathrm{~s})$.

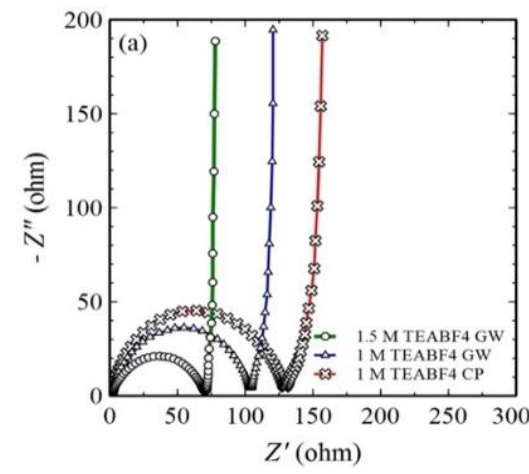

(a)

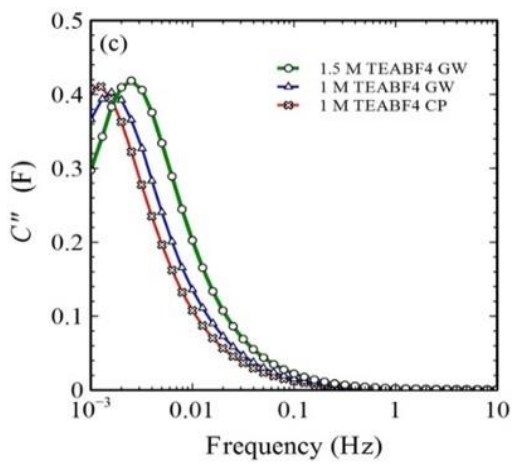

(c)

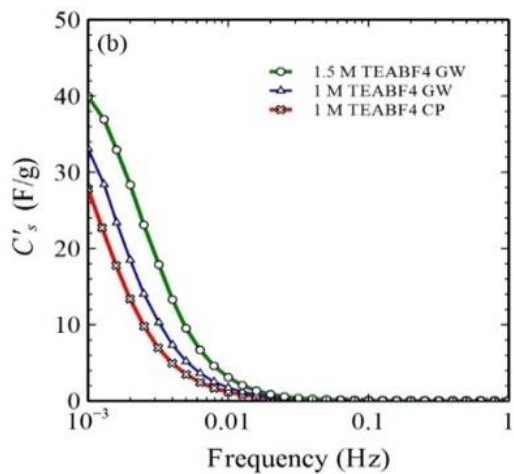

(b)

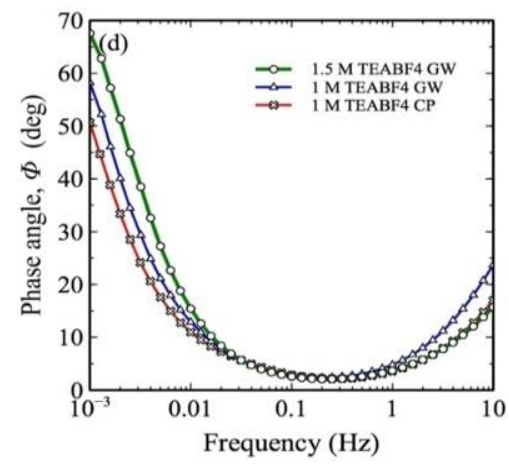

(d)

Figure 5. (a) Nyquist plots, (b) Specific capacitance versus frequency, (c) Imaginary part of the complex capacitance versus frequency, (d) Phase angle versus frequency

The power density and the energy density were calculated based on GCD results (also tabulated in Table 1) and plotted in Ragone plot shown in Figure 6. The curve of glass wool-based supercapacitor was found above the cellulose-based supercapacitor, indicating that the energy density of glass wool-based supercapacitor is improved. In terms of power density, the cellulose-based supercapacitor outperforms the one with glass wool due to its poor internal resistant measured from GCD test. Remarkably, at higher concentration of $\mathrm{TEABF}_{4}$, the curve of glass wool-based supercapacitor was apparently found above of the rest of supercapacitors indicating its much better performance in terms of power and energy densities. This finding implies supercapacitor with higher concentration of $\mathrm{TEABF}_{4}$ electrolyte possesses an improved accumulation process on the active electrodes due to its higher number of ions available, thus improving the capacitive properties of supercapacitor [24-25]. 


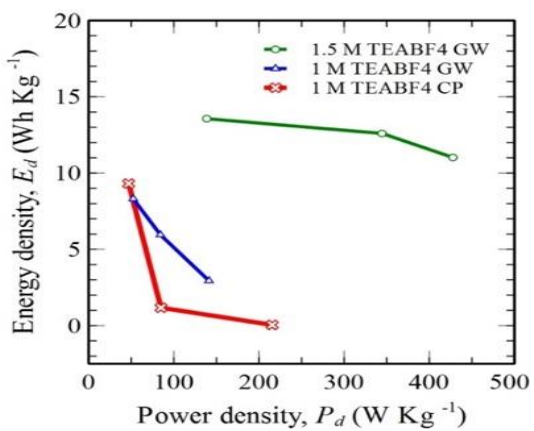

Figure 6. Ragone plots of the constructed supercapacitors

Table 1. Electrochemical data of the contructed supercapacitors from GCD, CV and EIS test

\begin{tabular}{|c|c|c|c|c|c|c|c|c|}
\hline \multirow{2}{*}{ Construction } & \multirow{2}{*}{ Parameter } & \multicolumn{3}{|c|}{$\mathrm{CV}$} & \multicolumn{3}{|c|}{ GCD } & \multirow{2}{*}{ EIS } \\
\hline & & $1 \mathrm{mV} / \mathrm{s}$ & $2 \mathrm{mV} / \mathrm{s}$ & $5 \mathrm{mV} / \mathrm{s}$ & $2 \mathrm{~mA}$ & $5 \mathrm{~mA}$ & $10 \mathrm{~mA}$ & \\
\hline \multirow{4}{*}{$\begin{array}{c}\text { Cellulose } \\
\& \\
1 \mathrm{M} \mathrm{TEABF}\end{array}$} & $C(\mathrm{~F} / \mathrm{g})$ & 74.6 & 51.1 & 34.1 & 36.8 & 4.6 & 0.2 & 27.8 \\
\hline & $R_{e s r}(\Omega)$ & - & - & - & 543.5 & 300.0 & 118.3 & 129.4 \\
\hline & $E_{d}(\mathrm{Wh} / \mathrm{kg})$ & 18.9 & 12.9 & 8.6 & 9.3 & 1.2 & 0.1 & 7.0 \\
\hline & $P_{d}(\mathrm{~W} / \mathrm{kg})$ & - & - & - & 46.9 & 85.0 & 215.5 & 197.0 \\
\hline \multirow{4}{*}{$\begin{array}{c}\text { Glass wool } \\
\& \\
1 \mathrm{M} \mathrm{TEABF} 4\end{array}$} & $C(\mathrm{~F} / \mathrm{g})$ & 83.6 & 61.8 & 45.2 & 32.8 & 23.5 & 11.6 & 33.1 \\
\hline & $R_{e s r}(\Omega)$ & - & - & - & 487.0 & 302.6 & 180.5 & 104.0 \\
\hline & $E_{d}(\mathrm{Wh} / \mathrm{kg})$ & 21.2 & 15.7 & 11.4 & 8.3 & 6.0 & 2.9 & 8.4 \\
\hline & $P_{d}(\mathrm{~W} / \mathrm{kg})$ & - & - & - & 52.3 & 84.2 & 141.2 & 245.1 \\
\hline \multirow{4}{*}{$\begin{array}{c}\text { Glass wool } \\
\& \\
1.5 \mathrm{M} \mathrm{TEABF}\end{array}$} & $C(\mathrm{~F} / \mathrm{g})$ & 85.5 & 64.4 & 45.8 & 53.1 & 49.3 & 43.1 & 39.9 \\
\hline & $R_{e s r}(\Omega)$ & - & - & - & 184.0 & 74.0 & 59.6 & 70.5 \\
\hline & $E_{d}(\mathrm{Wh} / \mathrm{kg})$ & 21.9 & 16.5 & 11.7 & 13.6 & 12.6 & 11.0 & 10.2 \\
\hline & $P_{d}(\mathrm{~W} / \mathrm{kg})$ & - & - & - & 138.5 & 344.5 & 427.7 & 361.7 \\
\hline
\end{tabular}

\section{CONCLUSION}

The results reveal that the application of glass wool material as separator in organic electrolyte help to reduce the bulk resistance of supercapacitor by $19.6 \%$, promoting more efficient ions transfer across active surface of electrode and significantly improves specific capacitance by $19.1 \%$. The application of $1.5 \mathrm{M}$ $\mathrm{TEABF}_{4}$ even further improves the overall performance of supercapacitor with glass wool separator by $32.2 \%$ reduction of bulk resistance and $61.9 \%$ increment in specific capacitance (GCD at $2 \mathrm{~mA}$ ) compared to $1 \mathrm{M} \mathrm{TEABF}_{4}$. The energy and power density are significantly improved by $64 \%$ and $165 \%$ respectively at 1.5 $\mathrm{M} \mathrm{TEABF}_{4}$. This shows that the low-cost material, glass wool material is a promising material to be used as commercial separator in developing much better supercapacitor in future.

\section{ACKNOWLEDGEMENTS}

The authors acknowledge the financial support from Universiti Teknologi Malaysia (Q.J130000.2523.15H89) and the Ministry of Education Malaysia (R.J130000.7809.4F613).

\section{REFERENCES}

[1] C. Zhong, Y. Deng, W. Hu, J. Qiao, L. Zhang, and J. Zhang, "A review of electrolyte materials and compositions for electrochemical supercapacitors," Chemical Society Reviews, vol. 44, pp. 7484-539, Nov 72015.

[2] Y. Wang, Y. Song, and Y. Xia, "Electrochemical capacitors: mechanism, materials, systems, characterization and applications," Chemical Society Reviews, vol. 45, pp. 5925-5950, Oct 242016.

[3] S. S. Zhang, "A review on the separators of liquid electrolyte Li-ion batteries," Journal of Power Sources, vol. 164, pp. 351-364, Jan 2007.

[4] K. Tõnurist, T. Thomberg, A. Jänes, T. Romann, V. Sammelselg, and E. Lust, "Influence of separator properties on electrochemical performance of electrical double-layer capacitors," Journal of Electroanalytical Chemistry, vol. 689, pp. 8-20, 2013.

[5] A. M. Bittner, M. Zhu, Y. Yang, H. F. Waibel, M. Konuma, U. Starke, et al., "Ageing of electrochemical double layer capacitors," Journal of Power Sources, vol. 203, pp. 262-273, 2012.

[6] Z. A. Noorden, S. Sugawara, and S. Matsumoto, "Noncorrosive separator materials for electric double layer capacitor," IEEJ Transactions on Electrical and Electronic Engineering, vol. 9, pp. 235-240, 2014.

[7] M. He, K. Fic, E. Frąckowiak, P. Novák, and E. J. Berg, "Influence of aqueous electrolyte concentration on parasitic reactions in high-voltage electrochemical capacitors," Energy Storage Materials, vol. 5, pp. 111-115, Oct 2016. 
[8] Q. Pan, W. Tu, L. Ding, and G. Mi, "Characteristics of electric double layer in different aqueous electrolyte solutions for supercapacitors," Wuhan University Journal of Natural Sciences, vol. 17, pp. 200-204, 2012.

[9] M. F. M. Yaacob, Z. A. Noorden and J. J. Jamian, "Charge-discharge cyclability of ultracapacitor with glass wool separator under high concentrated sulfuric acid," 2016 IEEE International Conference on Power and Energy PECo, Melaka, pp. 718-722, 2016,.

[10] M. F. M. Yaacob, Z. A. Noorden and J. J. Jamian, "Electrochemical impedance behavior of glass wool-based supercapacitors with different concentration of sulfuric acid," 2016 IEEE International Conference on Power and Energy PECon, Melaka, pp. 723-727, 2016.

[11] Z. A. Noorden, S. Sugawara, \& S. Matsumoto, "Glass wool material as alternative separator for higher rating electric double layer capacitor," ECS Transactions, vol. 53, pp. 43-51, 2013.

[12] H. Kurig, A. Jänes, and E. Lust, "Electrochemical Characteristics of Carbide-Derived Carbon|1-Ethyl-3methylimidazolium Tetrafluoroborate Supercapacitor Cells," Journal of The Electrochemical Society, vol. 157, p. A272, 2010.

[13] M. Selvakumar and S. Pitchumani, "Hybrid supercapacitor based on poly(aniline-co-m-anilicacid) and activated carbon in non-aqueous electrolyte," Korean Journal of Chemical Engineering, vol. 27, pp. 977-982, April 2010.

[14] A. Lewandowski, A. Olejniczak, M. Galinski, and I. Stepniak, "Performance of carbon-carbon supercapacitors based on organic, aqueous and ionic liquid electrolytes," Journal of Power Sources, vol. 195, pp. 5814-5819, Sep 2010.

[15] H. Randriamahazaka, and K. Asaka, "Electromechanical Analysis by Means of Complex Capacitance of BuckyGel Actuators Based on Single-Walled Carbon Nanotubes and an Ionic Liquid," The Journal of Physical Chemistry, vol. 114, pp. 17982-17988, 2010.

[16] P. L. Taberna, P. Simon, and J. F. Fauvarque, "Electrochemical Characteristics and Impedance Spectroscopy Studies of Carbon-Carbon Supercapacitors," Journal of The Electrochemical Society, vol. 150, pp. A292-A300, 2003.

[17] S. Yoon, J. H. Jang, B. H. Ka, and S. M. Oh, "Complex capacitance analysis on rate capability of electric-double layer capacitor (EDLC) electrodes of different thickness," Electrochimica Acta, vol. 50, pp. 2255-2262, April 2005.

[18] X. Zhang, X. Wang, L. Jiang, H. Wu, C. Wu, and J. Su, "Effect of aqueous electrolytes on the electrochemical behaviors of supercapacitors based on hierarchically porous carbons," Journal of Power Sources, vol. 216, pp. 290-296, Oct 2012.

[19] P. Yang, P. Sun, L. Du, Z. Liang, W. Xie, X. Cai, "Quantitative Analysis of Charge Storage Process of Tungsten Oxide that Combines Pseudocapacitive and Electrochromic Properties," The Journal of Physical Chemistry C, vol. 119, pp. 16483-16489, July 2015.

[20] P. K. Shen, C. Y. Wang, S. P. Jiang, X. Sun, and J. Zhang, "Electrochemical Energy: Advanced Materials and Technologies," CRC Press. pp. 451-477, 2015.

[21] H. E. Darling, "Conductivity of Sulfuric Acid Solutions". Journal of Chemical \& Engineering Data, vol. 9, no.3, pp. 421-426, 1964.

[22] T. Meng, K. H. Young, D. F. Wong, and J. Nei, "Ionic Liquid-Based Non-Aqueous Electrolytes for Nickel/Metal Hydride Batteries," Batteries, vol. 3, no. 1, p. 4, Feb 2017.

[23] K. C. Tsay, L. Zhang, and J. Zhang, "Effects of electrode layer composition/thickness and electrolyte concentration on both specific capacitance and energy density of supercapacitor," Electrochimica Acta, vol. 60, no. 15, pp. 428-436, Jan 2012.

[24] Z. A. Noorden, S. Sugawara, and S. Matsumoto, "Electrical Properties of Hydrocarbon-derived Electrolytes for Supercapacitors," IEEJ Transactions on Electrical and Electronic Engineering, vol. 7, no. S1, pp. S25-S31, 2012.

[25] Z. A. Noorden and S. Matsumoto, "Electrochemical Study of Hydrocarbon-Derived Electrolytes for Supercapacitors", Japanese Journal of Applied Physics, vol. 52 no. 10S, pp. 1-5, Oct 2013.

\section{BIOGRAPHIES OF AUTHORS}

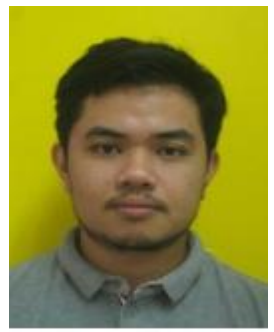

Mohd Ferdaus Mohammad Yaacob received his B. Eng degree from Universiti Teknologi Malaysia (UTM) Johor Bahru, Malaysia in 2011. He worked as a product development engineer in Intel Corporation Penang, Malaysia from 2011 to 2015 prior pursuing his M. Eng degree in UTM from the end of 2015. He continued to serve the same company with the same position after completing his M. Eng degree (research) in early 2018. His research interests include energy storage technology and material engineering.

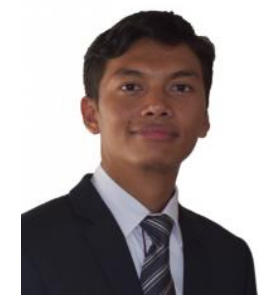

Zulkarnain Ahmad Noorden received the B.Eng. and M.Eng. degrees in Electrical Engineering from Universiti Teknologi Malaysia (UTM) in 2008 and 2009, respectively. In 2013, he completed his Ph.D. degree in Regional Environment System (Electrical Engineering) from Shibaura Institute of Technology, Tokyo, Japan. Currently, he is a Senior Lecturer at the Institute of High Voltage and High Current, UTM Johor Bahru, Malaysia. His research interests include ultracapacitor materials and technology, power equipment diagnosis, and high voltage generation. 


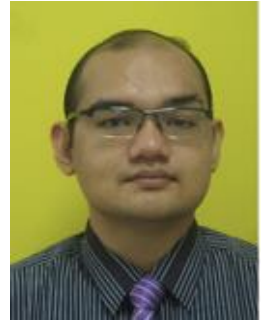

Muhammad Nizam Abdul Razak received the B. Eng degree from Universiti Malaysia Pahang (UMP) in 2013. He completed the M. Eng degree in electrical engineering from Universiti Teknologi Malaysia (UTM) in 2015. Currently, he is pursuing the Ph.D. degree at Universiti Teknologi Malaysia (UTM). His research interests include energy storage systems, power system dispatch and high-voltage generation.

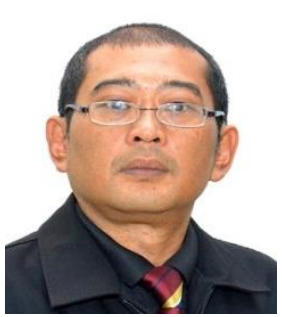

Muhammad Nizam Abdul Razak received the B. Eng degree from Universiti Malaysia Pahang (UMP) in 2013. He completed the M. Eng degree in electrical engineering from Universiti Teknologi Malaysia (UTM) in 2015. Currently, he is pursuing the Ph.D. degree at Universiti Teknologi Malaysia (UTM). His research interests include energy storage systems, power system dispatch and high-voltage generation.

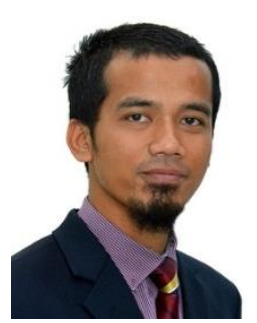

Jasrul Jamani Jamian received the B. Eng. (Hons) degree in electrical engineering in 2008, M. Eng. degree in Electrical Engineering (Power) in 2010 and Ph.D degree in Electrical Engineering (Power) in 2015 from Universiti Teknologi Malaysia (UTM), Johor Bahru, Malaysia. His current research interests include power system optimization, power system stability, and renewable energy applications and their control methods. 